\title{
Síndrome de compressão orbitária relacionada à anemia falciforme
}

\author{
Orbital compression syndrome in sicklecell disease
}

Eduardo Ferrari Marback ${ }^{(1)}$

Patrícia Maria Fernandes Marback ${ }^{(1)}$

Roberto Lorens Marback ${ }^{(2)}$

César Moreira Sampaio ${ }^{(3)}$

Danilo Cruz Sento Sé ${ }^{(4)}$
Alunos do Curso de Especialização em Oftalmologia da Faculdade de Medicina da Universidade Federal da Bahia. Atualmente pós-graduandos em Oftalmologia da Escola Paulista de Medicina. Universidade Federal de São Paulo.

(2) Professor Adjunto Doutor. Faculdade de Medicina da Universidade Federal da Bahia. Chefe do Serviço de Oftalmologia do Hospital São Rafael. Fundação Monte Tabor. Salvador - Bahia.

(3) Médico Assistente do Serviço de Oftalmologia do Hospital São Rafael. Fundação Monte Tabor. Salvador - Bahia.

(4) Professor Auxiliar. Faculdade de Medicina da Universidade Federal da Bahia. Coordenador do Serviço de Oftalmologia do Hospital São Rafael. Fundação Monte Tabor. Salvador - Bahia.

\section{RESUMO}

Objetivo: Relatar caso raro de síndrome de compressão orbitária bilateral secundária a hematoma subperiósteo em criança portadora de anemia falciforme.

Métodos: Relato de caso de criança aos 08 anos de idade, com anemia falciforme (eletroforese de hemoglobina-SS) e síndrome de compressão orbitária bilateral assimétrica apresentando-se com hematomas extradurais espontâneos, proptose e dor em ambos os olhos. Evoluiu com remissão completa dos sinais e sintomas em 20 dias apenas com tratamento sintomático. São apresentados os exames de imagem da fase aguda e após resolução do quadro clínico.

Conclusão: Anemia falciforme deve ser incluída entre as causas de síndrome de compressão orbitária.

Palavras-chave: Síndrome de compressão orbitária; Anemia falciforme; Exoftalmo.

\section{INTRODUÇÃO}

Oclusões vasculares recorrentes são freqüentemente associadas à anemia falciforme, causando sintomatologia variada dependente de lesões hipóxicas ou infartos em vários orgãos e tecidos. Embora alterações clássicas tanto de segmento anterior como posterior sejam descritas ${ }^{1}$, são raros os relatos de manifestações orbitárias da anemia falciforme.

$\mathrm{O}$ estudo de um paciente portador de anemia falciforme apresentando síndrome de compressão orbitária bilateral, secundária a hematoma subperiósteo em ambas as órbitas motivaram esse relato.

\section{APRESENTAC̄̃̃O DO CASO}

J. S. J., 08 anos, masculino, estudante, natural e procedente de Salvador Bahia. Registro 2621150 do Hospital São Rafael. Salvador, Bahia.

Encaminhado do serviço onde fora internado por vinte dias com "edema e dor" em ambos os olhos, protusão do globo ocular esquerdo e desorientação. O paciente tinha diagnóstico prévio de Anemia Falciforme (com eletroforese de hemoglobina SS). Durante o internamento fez uso de ceftriaxona; dexametasona; analgésicos a base de uma combinação de acetaminofen e codeína; ácido fólico, e pomada oftálmica contendo tobramicina em ambos os olhos, com curativo oclusivo em olho esquerdo. Evoluiu com regressão do edema do olho direito e manutenção da proptose a esquerda.

Ressonância Magnética de crânio revelou imagens sugestivas de he- 
matomas extra-durais na região frontal, sendo uma mediana com cerca de $1,9 \mathrm{~cm}$ de espessura, uma lateral direita com 1,2 $\mathrm{cm}$, e outra lateral esquerda com $0,8 \mathrm{~cm}$ de espessura (Fig. 1).

Tomografia computadorizada das órbitas revelou formações expansivas sólidas, homogêneas, não captantes, de contornos lobulados crescendo a partir da fossa lacrimal de ambas as órbitas, (Fig. 2) deslocando medial e inferiormente os músculos reto lateral e superior, principalmente à esquerda, onde há também compressão do nervo óptico. Assinala-se também deslocamento anterior e inferiormente dos globos oculares, em especial à esquerda. As lesões medem aproximadamente: direita 2,8 x 1,8 x 1,8 cm; esquerda 3,5 x 3,0 x 2,0 cm. Não causam erosão nem remodelam as estruturas ósseas contíguas. Ultrassonografia de abdome total não revelou achados patológicos.

Ao ser atendido em nosso serviço apresentava exoftalmo axial à esquerda e não havia limitações dos movimentos oculares. A pupila do OE apresentava-se em midríase média, reflexo

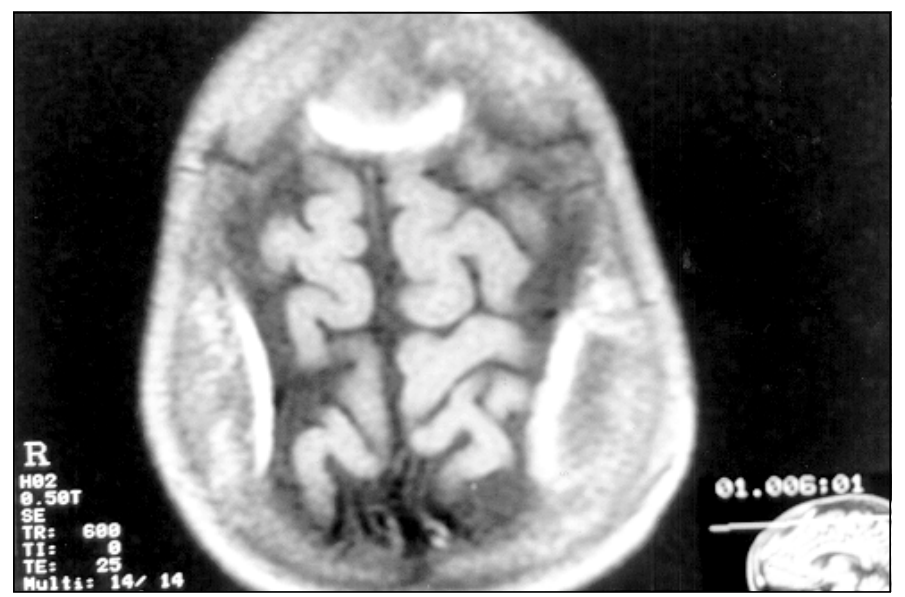

Fig. 1 - A ressonância magnética revelou a presença de imagens compatíveis com hematomas extra-durais intracranianos.

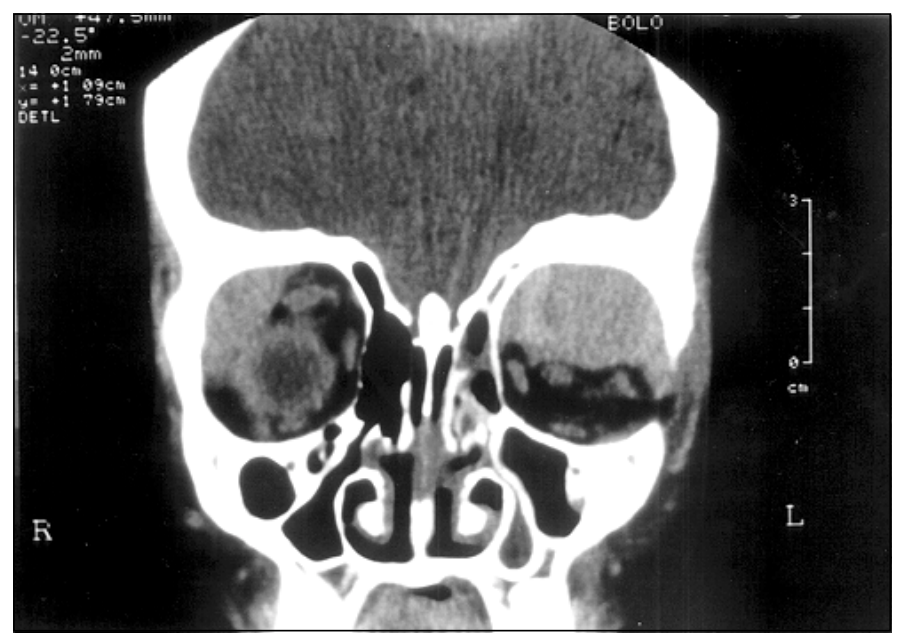

Fig. 2 - Tomografia computadorizada das órbitas, evidencia formações expansivas levemente hiperdensas, não captantes, na porção súperolateral de ambas as órbitas. fotomotor direto lento e pronto reflexo consensual. A acuidade visual era igual a 1,0 em OD; e de 0,5 em OE. Tonometria e fundoscopia normais.

Face à gradual diminuição da exoftalmia à esquerda e do desaparecimento da exoftalmia à direita optamos por acompanhar a evolução do paciente sem modificações terapêuticas.

Vinte dias após a acuidade visual em OE era igual a 1,0 e havia regressão total do exoftalmo à esquerda. Tomografia computadorizada de crânio e órbitas nesta época revelaram resolução da formação expansiva na órbita esquerda, pequena imagem residual superiormente em órbita direita (Fig. 3) e calcificações presentes na área mediana previamente ocupada por um dos hematomas sub-durais.

\section{DISCUSSÃO}

Hematomas peri-orbitários podem ser causados por trauma, infecção peri-orbitária, nefrite, exoftalmopatia tireoidiana, doenças da glândula lacrimal, glaucoma, edema angioneurótico, tracoma, discrasias sangüíneas, infiltração leucêmica, neuroblastoma metastático, dermatomiosite e trombose de seio cavernoso ${ }^{2}$. Tais autores mencionaram não ter encontrado a inclusão de infartos ósseos peri-orbitários entre o diagnóstico diferencial dos hematomas nesta região. Infartos ósseos estão freqüentemente associados à anemia falciforme. No entanto, usualmente os ossos longos são mais acometidos ${ }^{3}$.

Em recente revisão dos casos descritos na literatura ${ }^{3}$ a síndrome de compressão orbitária (SCO) é caracterizada como proptose, limitação da motilidade ocular, anestesia peri-ocular e/ou diminuição da acuidade visual. Nos pacientes com as diferentes formas de doenças que causam deformidade em foice das hemácias (SS, SC e S talassêmia) tal condição pode ser causada por infarto dos ossos orbitários com resultante formação de hematomas subperiostais; retro-bulbares; intracranianos e/ou nos seios da face. A média de idade durante o

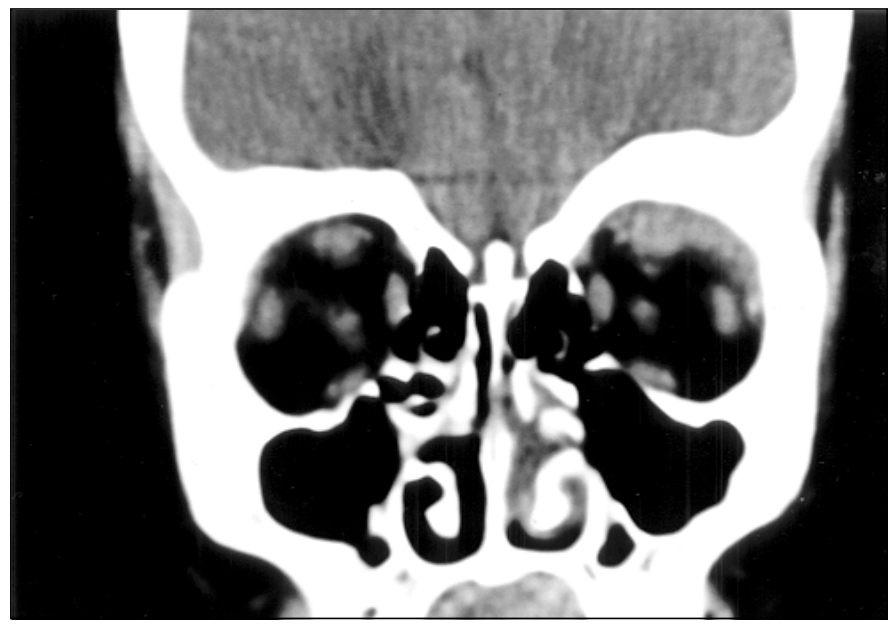

Fig. 3 - Tomografia computadorizada realizada vinte dias após o primeiro exame revelou resolução da formação expansiva em órbita esquerda e imagem residual superiormente em órbita direita. 


\section{ANÚNCIO}


episódio de SCO é de 12,8 anos, e a presença de medula óssea proeminente nos ossos chatos da órbita nesta faixa etária parece justificar esse achado.

$\mathrm{O}$ diagnóstico diferencial entre osteomielite e $\mathrm{SCO}$ em portadores de anemia falciforme é bastante difícil. Comumente os pacientes são crianças que se apresentam ao serviço de emergência com edema periorbitário, quemose e febre com tempo de instalação usualmente menor que 24 horas $^{3}$. A cintilografia óssea com Tecnécio 99 e Gállium 67 parece ser o único exame auxiliar de valia para diferenciar osteomielite de infarto ósseo. No infarto ósseo a área afetada mostrará uma deficiência de atividade à cintilografia, enquanto na osteomielite ocorrerá o inverso ${ }^{2}$.

A conduta frente a um paciente com anemia falciforme e SCO inclui medidas de suporte como hidratação e analgesia. Em todos os casos descritos na literatura encontramos o uso empírico de antibióticos de amplo espectro. Alguns autores advogam a drenagem cirúrgica caso haja comprometimento da função visual ou um hematoma de grande proporção ${ }^{3}$. Esses autores justificam tal conduta baseados num tempo de recuperação mais rápido nos casos operados (menor que 02 semanas em comparação com 04 a 08 nos casos mais severos manejados conservadoramente) e na proteção à função visual. No entanto, nesta mesma revisão todos os pacientes manejados clinicamente recuperaram acuidade visual de 20/20 e motilidade ocular plena, a exceção de um paciente que na crise aguda tinha acuidade visual em um dos olhos de projeção luminosa e recuperou melhor acuidade visual corrigida de 20/25 (embora não faça menção à acuidade visual prévia). Frente a esses dados é importante pesar as possíveis complicações do ato cirúrgico, além dos riscos de uma anestesia geral, principalmente tratando-se de crianças com anemia falciforme na qual hipóxia, hipotermia e acidose podem gerar mais deformação de hemácias levando a outras lesões teciduais ${ }^{4}$.

No caso ora relatado, como a criança já vinha apresentando melhora progressiva do quadro ocular e resolução da sintomatologia neurológica, a opção foi pela conduta expectante. Em aproximadamente 20 dias o paciente já havia recuperado completa função visual, sem qualquer tipo de seqüela ao exame oftalmológico.
Não temos conhecimento de outro caso de SCO associada à anemia falciforme descrito na literatura oftalmológica brasileira. Entretanto, não é improvável que o oftalmologista seja o primeiro médico a avaliar um paciente com exoftalmo de aparecimento rápido e, principalmente em se tratando de paciente jovem, o diagnóstico de anemia falciforme (muitas vezes ignorado pelo próprio paciente) e SCO deve fazer parte das suspeitas diagnósticas.

\section{SUMMARY}

Purpose: To present a case of bilateral orbital compression syndrome secondary to subperiosteal hematoma in sickle cell disease.

Methods: Case report of a child with sickle cell disease and asymmetric bilateral orbital compression syndrome, with extradural hematomas, ocular pain and proptosis. There was remission of symptoms and signs in about 20 days with symptomatic treatment alone. Radiological aspects in the acute and remission phases are presented. Conclusion: Sickle Cell disease should be included as a cause of orbital compression syndrome.

Keywords: Orbital compression syndrome; Sickle cell disease; Exophthalmos.

\section{REFERÊNCIAS BIBLIOGRÁFICAS}

1. Gagliano DA, Jampol IM, Rabb MF. Sickle Cell Disease. In: Duane's Ophthalmology. Clinical Volume III, Chapter 17. 1998 CD-Rom Edition. Lippincott-Raven.

2. Garty I, Koren A, Gardozi H. Frontal and Orbital Bone Infarctions Causing Periorbital Swelling in Patients with Sickle Cell Anemia. Arch Ophthalmol 1984;102:1486-8.

3. Curran EL, Fleming JC, Rice K, Wang WC. Orbital Compression Syndrome in Sickle Cell Disease. Ophthalmology 1997;104:1610-5.

4. Scott-Conner CEH, Brunson CD. The Pathophysiology of the Sickle Hemaglobinopathies and Implications for Perioperative Management. Am J Surg 1994;168:268-74.

\section{Novidades na Internet:!:}

Agora no site CBO você tem disponível todas as informações na íntegra dos

Arquivos Brasileiros de Oitalmologia

httpa//ww w.cbo.com.br/abo 